\title{
L'IMMAGINE MARIANA NELLA COMEDIA NUEVA
}

\author{
POR \\ LUIGI PATRUno \\ Colegio de Jalisco ،(México)
}

\section{RESUMEN}

La Comedia Nueva es un género realmente no religioso. La presencia de temas cristianos en estas representaciones, entonces, nos ofreces la posibilidad de sacar diferentes consideraciones acerca de las actitudeds de los autores y espectadores de las comedias en la España del Siglo de Oro. En nuestro trabajo hemos estudiado tres comedias marianas del siglo XVII de tres diferentes autores fijandonos en las imágenes sagradas y sus cultos, en como la veneración a ellas halla sitio en el teatro y en los comportamentos de los autores. Objeto de nuestro estudio ha sido el drama de Calderón de la Barca Origen, pérdida y restauración de la Virgen del Sagrario, la obra del semi-desconocido Antonio Fajardo y Acevedo Origen de Nuestra Señora de las Angustias y la comedia Nuestra Señora de Atocha de Francisco de Rojas Zorilla.

PAlabras Clave: Culto a las imágenes marianas, Historia de las imágenes cristianas, Comedia Nueva española, Teatro e imágenes sagradas, Milagro mariano

\begin{abstract}
Comedia Nueva is not really a religious genre. Thus the presence of christian subjects in this kind of plays offer us many consideration about the writers and their audience in Spain of the Golden Century. In our work we studied three Marian Plays of three different writers. We put our attention on the sacred images and their cults, on the way their veneration take place in the Theatre and the manners of the writers. The object of our study has been the drama Origen, pérdida y restauración de la Virgen del Sagrario written by Calderón de la Barca, the play Origen de Nuestra Señora de las Angustias by the hardly known Antonio Fajardo y Acevedo and Nuestra Señora de Atocha composed by Francisco de Rojas Zorilla.
\end{abstract}


KEY WORDS: Cult of the marian images, History of the christian images, Spanish Comedia Nueva, Theatre and sacred images, Marian miracle

\section{CALDERÓN DE LA BARCA. ORIGEN, PÉRDIDA Y RESTAURACIÓN DE LA VIRGEN DEL SAGRARIO.}

L'opera di Calderón dal titolo Origen, pérdida y restauración de la Virgen del Sagrario vide la luce nel 1637, ma probabilmente era stata composta dal poeta già qualche tempo prima ${ }^{1}$. Calderón scrisse il dramma dopo essere stato a Toledo e in occasione della sua permanenza in quella città ebbe sicuramente la possibilità di consultare gli archivi della cattedrale. Fu lì che trovò tutta la serie di fonti che adoperò per la stesura del dramma, tra cui quella che costituisce la sua influenza principale, il Sagrario de Toledo, un poema eroico scritto da Joseph de Valdivielso, un cappellano di Toledo ${ }^{2}$. A questo componimento Calderón deve soprattutto l'idea generale del suo dramma, ma da quello si è lasciato influenzare anche per ciò che riguarda il racconto della scoperta dell'immagine della Vergine, nonché per la descrizione del simulacro alla fine del terzo atto. Nel poema di Valdivielso inoltre si fa riferimento anche a Ildelfonso e all'eresia di Pelagio e Teudio, entrambi elementi che compaiono nell'opera calderoniana. Tra l'altro in tutte e due le opere si fa riferimento all'episodio leggendario dell'investitura con la casula di Ildelfonso da parte della Vergine ${ }^{3}$. Tra le numerose fonti che vennero utilizzate a sua volta da Valdivielso vale la pena ricordare il Flos Sanctorum di Pedro de Ribadeneyra, continuazione del Flos Sanctorum di Alonso di Villegas, opera che sostituì a livello di fonti agiografiche «la vecchia Leggenda aurea, distinguendosi da essa per la conformità al Breviario romano, riformato dal decreto del Concilio di Trento» ${ }^{4}$.

L'opera di Calderón si apre con la leggenda dei re visigoti e della caverna di Ercole: nessun re avrebbe dovuto aprire le porte che chiudevano quella grotta, pena lo scatenarsi di tremende sciagure. Ma alcuni anni dopo il regno di Recesvindo, colui che pose il primo sigillo sulle porte della caverna, un molle quanto incosciente Roderico, ultimo sovrano visigoto, schiuse quelle porte segrete e questa temerarietà fu la causa, secondo la leggenda, della perdita

\footnotetext{
1 Egidio GORRA, Fra drammi e poemi, Milano 1990, p. 412.

2 Pedro CALDERÓN DE LA BARCA, «Origen, pérdida y restauración de la Virgen del Sagrario», in Obras. Tomo I: Dramas, a cura di Ángel VALBUENA BRIONES, Madrid 1944-1945, p. 248.

3 Ibidem, p. 250.

${ }^{4}$ Brenda DUNN-LARDEAU, «Le conseguenze dell'Umanesimo e del Concilio di Trento sulla scrittura agiografica», in Erudizione e devozione. Le raccolte di Vite di santi in età moderna e contemporanea, a cura di Gennaro LUONGO, Roma 2000, p. 28.
}

Poder y religión en la Hispania Medieval y Moderna Hispania Sacra 56 (2004) 
della Spagna per mano degli arabi. Subito dopo il racconto leggendario viene introdotto uno dei protagonisti del primo atto, Ildelfonso, e a questi viene legata la lotta della Chiesa contro l'eresia di Pelagio e Teudio. Nella chiesa di santa Leocadia a Toledo, dove si svolge l'azione, Ildelfonso che è un devoto servo della Vergine chiede al re di istituire una festa che esalti la verginità di Maria. L'idea della festa della Sagrada Expetación piace al sovrano che s'impegna per questo a scrivere al pontefice in persona affinché questi possa concedere il nuovo rito. La regina chiede a Ildelfonso che origine abbia l'immagine della Vergine che si venera in quella chiesa e a questa richiesta segue il racconto sulle misteriose radici della Virgen del Sagrario. Alla storia dell'immagine della Vergine è legata la storia di Toledo ed ecco che finito il racconto d'Ildelfonso si ode una voce cantante che precede un miracolo. Il sepolcro che contiene i resti di santa Leocadia si apre e la martire esce da quello per parlare a Ildelfonso. Il primo atto termina con la sfilata di un carro su cui la Vergine stessa è circondata da angeli festosi. Maria veste Ildelfonso di una casula tra le lodi dei presenti.

Nel secondo atto si assiste ad un cambio brusco di tempo. L'azione si svolge sempre a Toledo ma siamo nell'epoca della conquista araba della Spagna. I musulmani sono alle porte della città, il vescovo Urbano scappa via da Toledo e mette in salvo le preziose reliquie conservate nella città ma non riesce a prendere l'immagine della Vergine che si rifiuta di lasciare la «sua» Toledo. Alla fine dell'atto sarà l'alcalde ad interrare l'immagine che rischia la profanazione degli arabi e la nasconde in un pozzo.

Il terzo atto si apre con un ulteriore cambio di tempo. Toledo è ora riconquistata da Alfonso VI. Mori e cristiani convivono pacificamente in comunità e ai primi il re concede la libertà di culto in quella che un tempo fu la chiesa di santa Leocadia, lì dove era stata segretamente nascosta l'immagine della Vergine. La regina con la complicità del vescovo Bernardo si riappropria del tempio suscitando il malcontento generale degli arabi che ora accusano il sovrano di non avere mantenuto la sua promessa, quella di concedere il santuario di Santa Leocadia per esercitare il loro culto. Il re decide di uccidere la regina perché il suo onore non venga macchiato di quest'infamia ma quando giunge al tempio di santa Leocadia assiste al ritrovamento miracoloso della Virgen del Sagrario. L'immagine, l'antica patrona di Toledo, tirata su dal fondo del pozzo viene portata in processione e in questo modo si conclude il dramma.

L'opera di Calderón ha una struttura molto particolare. Ognuno degli atti può essere considerato come un dramma a sé stante: gli unici collegamenti tra le tre parti sono il protagonismo dell'immagine a cui si riferiscono tutte le vicende e la città di Toledo, città in cui si svolge l'azione. E infatti in questo dramma Calderón ha voluto esaltare le vicende leggendarie legate alla Virgen del Sagra- 
rio ma anche la città di Toledo, e tra questi due oggetti del suo elogio, come vedremo, ha posto forti vincoli. Per il resto tutto lascia pensare che gli atti siano indipendenti tra loro. Il cambio di personaggi ne è una prova. A parte la Virgen del Sagrario non c'è nessuno personaggio in comune. Il tempo anche è un indice dell'indipendenza tra gli atti: il primo si svolge in epoca visigota, il secondo in epoca araba e il terzo in tempi cristiani, nel periodo della Riconquista.

\section{LA VIRGEN DEL SAGRARIO: PATRONA DI TOLEDO.}

Nel primo atto Ildelfonso fa un lungo racconto sull'origine misteriosa dell'immagine della Vergine venerata a Toledo. Curiosamente il nucleo centrale di questa narrazione, quello cioè in cui si spiega come l'immagine sia giunta nella città di Toledo, chi l'abbia fatta e a chi sia appartenuta, è preceduto da un racconto sull'origine della città di Toledo. L'oscurità che avvolge l'origine dell'immagine e l'elogio della città che la ospita, in questo modo s'intrecciano. Telamón, Bruto, Rocas Rey, il negromante Florencio: Calderón non dimentica di offrire nessun carattere leggendario dei possibili fondatori di Toledo. Tra questi nomi cita quello di Nabucodonosor come il più probabile tra i fondatori della città. Nel medesimo racconto le parole di Ildelfonso lasciano intendere che Toledo consideri proprio l'immagine del Sagrario come «porto dei suoi tormenti»:

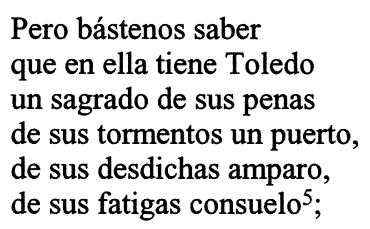

Si capisce come la città stessa abbia eletto l'immagine sua patrona. Ma questo rapporto di dipendenza è contraccambiato. Nel secondo atto Teodosio, il vecchio della città, rivela che il vescovo Urbano è scappato dalla città invasa dagli arabi e ha portato in salvo le reliquie che Toledo conservava. Questi oltre che i resti dei santi ha cercato di portar via anche l'immagine del Sagrario, ma il tentativo non gli è riuscito perché la patrona di Toledo non si è lasciata prendere:

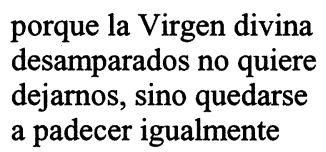

5 Pedro CALDERÓN DE la BARCA, «Origen, pérdida...», cit., p. 256.

Poder y religión en la Hispania Medieval y Moderna

Hispania Sacra 56 (2004) 
nuestras penas; que hasta en esto

toledana se parece 6 .

Se quindi Toledo trova riparo dai suoi tormenti nella Virgen del Sagrario, dunque, anche l'immagine decide di restare e soffrire le stesse pene dei toledani attaccati dagli arabi:

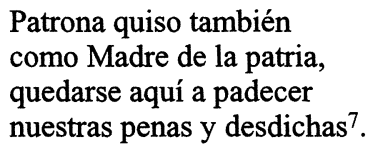

Il tema si conclude con il finale ritrovamento dell'immagine, impresa simbolica della riconquista di Toledo e della cristianizzazione del suo spazio. Nel corso del terzo atto viene sottolineata da una parte la capacità di convivenza tra mori e cristiani, mentre dall'altra è enfatizzata l'impresa della presa di Toledo a cui è legata la riconquista del tempio di santa Leocadia «casa y ciminento / de la fe» ${ }^{8}$. Quando viene ritrovata l'immagine, la regina Doña Costanza si lascia prendere da un forte sentimento di possessione:

$$
\begin{aligned}
& \text { ¡Mira, si no hubiera yo } \\
& \text { quitado el templo al cobarde } \\
& \text { moro, el bien de que era dueño! }
\end{aligned}
$$

Il ritrovamento dell'immagine rafforza questo sentimento nazionale, legato certo alla riconquista della città, ma anche alla scoperta dell'immagine sua patrona. Essa contribuisce a cristianizzare lo spazio e costituisce la «concordia della comunità» ${ }^{10}$. Non solo il progressivo riappropriarsi dello spazio cooperava alla creazione delle coscienze nazionali, ma anche la venerazione delle immagini cristiane impiantava una nuova organizzazione spaziale, quella dei santuari custodi delle sacre immagini, nuclei importanti attorno ai quali la comunità s'identifica ${ }^{11}$. Calderón nel suo dramma enfatizza questa corrispondenza tra il movimento di riconquista e la venerazione dell'immagine mariana, entrambi mezzi contribuenti alla creazione della coscienza nazionale.

6 Ibidem, p. 265.

7 Ibidem, p. 268.

8 Ibidem, p. 255.

9 Ibidem, p. 280

10 Peter BROWN, Il culto dei santi, Torino 1983, p. 134-135. Nel suo libro Brown indica le reliquie dei martiri come «concordia della comunità» ma evidentemente negli intenti, l'immagine sacra della Virgen del Sagrario, rispecchia quella caratteristica segnalata da Brown. L'immagine mariana allo stesso modo delle reliquie dei martiri favorisce il processo di unione dei membri di una comunità.

${ }^{11}$ Luigi CANETTI, Frammenti di eternità, Roma 2002, p. 146. 


\section{L'IMMAGINE ACHEROPITA.}

L'immagine della Virgen del Sagrario non è opera di comuni mortali. Non è stato un artista né un artigiano l'artefice della statua. La sua origine è avvolta da un'oscura atmosfera soprannaturale e il tempo mitico in cui viene collocata contribuisce ad amplificare l'imperscrutabilità del suo mistero:

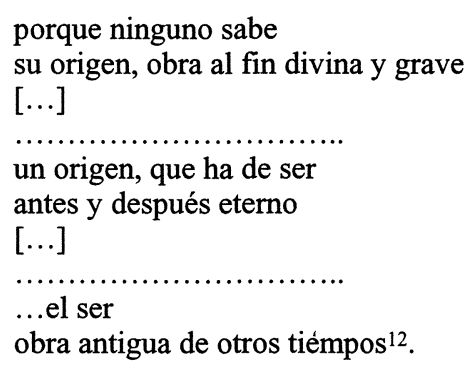

Calderón insiste sulla nozione temporale dell'origine della statua. Ponendo l'immagine al confine coi tempi memorabili e annullando addirittura il concetto di tempo che «non» sta all'origine della statua della Virgen del Sagrario, un'origine che è «prima e dopo eterna», crea uno spazio tra i fedeli e l'immagine stessa che da una parte ne giustifica o meglio ne rende percepibile e credibile la soprannaturalità, mentre dall'altro elude le attendibilità filologiche del racconto. Oltre che all'artefice, non si conosce nemmeno il nome di chi per la prima volta ha collocato nella chiesa di santa Leocadia la sacra immagine:

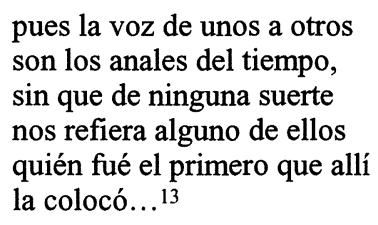

È solo ad una lunga tradizione orale che rimontano le informazioni su l'immagine. Calderón accenna alla «obra al fin divina y grave», ma ne parla meglio più tardi:

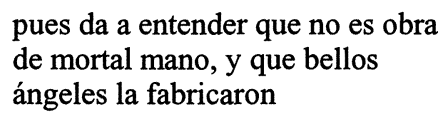

12 Pedro CALDERÓN DE LA BARCA, «Origen, pérdida...», pp. 255-256.

${ }^{13}$ Ibidem, p. 255.

Poder y religión en la Hispania Medieval y Moderna Hispania Sacra 56 (2004) 


\section{$[\ldots]$ para que al ángel más puro se atribuya su deidad ${ }^{14}$}

Si tratta dunque di un'immagine acheropita ${ }^{15}$, non fatta, cioè, da mano umana ma risultato di un miracolo divino, di un intervento in qualche modo soprannaturale. L'origine della credenza nelle immagini acheropite si perde nel tempo e non appartiene alla sola tradizione cristiana. Presso i greci molte statue come ad esempio l'Artemide venerata ad Efeso erano credute opera non di comuni mortali, ma scese dal cielo ${ }^{16}$. È però nella tradizione iconografica cristiana che assumono una risonanza particolare, specialmente in funzione antiiconoclasta ${ }^{17}$ e di palladio ${ }^{18}$. Le immagini acheropite possono essere di due tipi: «immagini ritenute opere di una mano diversa da quella dei comuni mortali oppure ritenute impronte meccaniche, ancorché miracolose dell'originale ${ }^{19}$. Quella della Virgen del Sagrario appartiene al primo tipo di acheropite essendo stata fatta da «angeli belli». L'intervento degli angeli nella realizzazione delle acheropite non è fatto nuovo. Basterà ricordare la tradizione che vuole un prodigioso intervento soprannaturale a compimento del Volto Santo, il crocifisso «mai scolpito e che si diceva fatto da Nicodemo e completato da un angelo ${ }^{20}$ venerato a Lucca. L'immagine di Calderón, alla stregua dell'Artemide di Efeso, discende dai cieli:

Y así esta divina imagen

Aun del solar de los cielos

14 Ibidem, pp. 255-257

15 Per l'origine e l'evoluzione del termine «acheropita»: Maria ANDAROLO, «L'acheropita in ombra del Laterano", in Il volto di Cristo. Roma, Palazzo delle Esposizioni, 9 dicembre 2000 - 16 aprile 2001, a cura di Giovanni MORELLO e Gerhard WOLF, Milano 2000.

16 Egon SENDLER, L'icona, immagine dell'invisibile, Cinisello Balsamo 1985, p. 15.

17 L'importanza dei temi proposti dalle immagini acheropite nell'ambito della crisi iconoclasta, è stata più volte sottolineata. Maria Andarolo, ad esempio, ricorda il peso che ebbero gli argomenti delle acheropite durante le sessioni del secondo concilio di Nicea (Maria ANDAROLO, «L'acheropita in ombra del Laterano», cit., p. 44); «tutte queste immagini sono, come si è detto, acheropite. Questa caratteristica le salva dagli attacchi degli iconoclasti: non sono stati gli uomini a dipingere il volto di Cristo, è stato egli stesso a lasciarcelo. La venerazione di queste immagini ha fatto sì che non sorgessero problemi teologici e che esse si conservassero fino a noi» (Jorge M. MEJ́A, «Vedere il volto di Cristo", in Il volto di Cristo, cit., p. 15).

18 André GRABAR, Martyrium. Iconographie, Paris 1946, p. 352.

19 Ernst KITZINGER, Il culto delle immagini, Firenze 1992, p. 44.

20 Genoveffa PALUMBO, «Immagini e devozione. Gli antichi modelli delle immagini di devozione tra predicazione e missione», in Santità, culti, agiografia. Temi e prospettive. Atti del I convegno di studio dell'Associazione italiana per lo studio della santità, dei culti e dell'agiografia. Roma, 24-26 ottobre 1996, a cura di Sofia BOESH GAJANO, Roma 1997, p. 195. 
No quiere probar nobleza, puesto que desciende dellos ${ }^{21}$;

La tradizione orale raccolta da Colderón vuole che sia stato il vescovo Eugenio il primo a portarla nella città. L'immagine era prima di lui appartenuta a Dionisio il quale a sua volta la ebbe dagli apostoli. Questi come noto portavano sempre con loro immagini della Vergine, fatte sull'originale stesso di Maria ${ }^{22}$ :

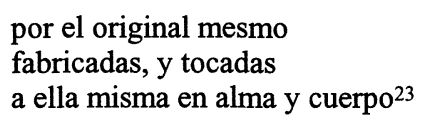

Ad amplificare l'enigma che ruota attorno all'origine dell'immagine si aggiunge la materia di cui è composta:

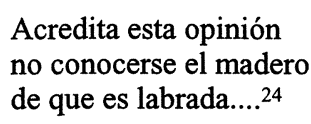

Calderón specifica di che materiale è la statua della Vergine, il legno, ma non ne chiarisce il tipo. Essendo l'origine della Virgen del Sagrario misteriosa, Calderón si appoggia poi a più forti e meglio giustificate tradizioni di altre immagini venerate nella penisola iberica, perché possano sostenere, ad esempio, l'ipotesi dell'appartenenza agli apostoli della Virgen del Sagrario. Sostiene infatti che la somiglianza nella posa di questa (la Virgen del Sagrario è rappresentata seduta in trono) con altre immagini spagnole, la cui origine è facilmente riconducibile agli apostoli, possa essere ritenuta prova del fatto che sia appartenuta ai dodici discepoli di Cristo. Non accaso poco prima si era accennato al fatto che gli apostoli solevano portare con loro «imágenes» della Vergine. Calderón cita una statua venerata a Madrid (Nuestra Señora de Atocha) e seduta in trono nello stesso modo, portata in Spagna da un discepolo di Pietro da Antiochia; la Vergine di Almudena ${ }^{25}$; quella di Astorga; quella della città di Lamego, in Portogallo, e un crocifisso dello stesso materiale della Virgen del Sagrario venerato a Túy.

\footnotetext{
21 Pedro CALDERÓN DE LA BARCA, «Origen, pérdida...», p. 256.

22 Più avanti, nell'ambito dell'opera di Rojas Zorilla, si parlerà della tradizione che vuole san Luca autore di un ritratto dal vivo della Vergine, immagine appartenuta in seguito agli apostoli.

23 Pedro CALDERÓN DE LA BARCA, «Origen, pérdida...», p. 256.

24 Idem.

${ }_{25} \mathrm{Nel} 1631$ venne rappresentato l'auto sacramental di Calderón dal titolo El cubo de la Almude$n a$ e che tratta delle leggende della santa immagine ai tempi della Riconquista (Pedro CALDERÓN DE LA BARCA, «El cubo de la Almudena», in Obras. Tomo III: Autos sacramentales, a cura di Ángel VALBUENA BRIONES, Madrid 1952, pp. 559-586).
}

Poder y religión en la Hispania Medieval y Moderna Hispania Sacra 56 (2004) 


\section{ANTONio FAJARDo y ACEVEDo. ORIGEN DE NuESTRA SEÑORA DE LAS AN- GUSTIAS.}

Nella seconda metà del Seicento è attivo in Spagna il commediografo Antonio Fajardo y Acevedo. Non si hanno molte notizie su di lui ${ }^{26}$; ignoriamo ad esempio dove sia nato ${ }^{27}$, ma sappiamo che fu sempre viva in lui la problematica religiosa tanto che decise di diventare eremita. Nel 1652 ottenne a Madrid il diploma di «Maestro del arte de leer, escribir y contar» ${ }^{28}$ e da quel momento in poi dedicò diversi sforzi nella scrittura teatrale. Va puntualizzato, comunque, che seppur la scrittura teatrale occupi la maggior parte della produzione di Fajardo Acevedo, non è tuttavia la sola ${ }^{29}$. Occorre segnalare infatti le opere di carattere storico come ad esempio il Resumen historial de las edades del mundo o la Relación Universal de todo el imperio Ottomano in otto libri. Quest'ultima opera ci offre ottimi spunti di riflessione circa il fascino che $\mathrm{Fa}$ jardo Acevedo dovette subire relativamente alla storia degli ottomani, personaggi presenti anche in diverse delle sue commedie. Oltre a queste opere vanno aggiunti diversi romances composti in diverse occasioni, una zarzuela (La flor, el ave y la fiera) e altre opere poetiche.

La preoccupazione religiosa non smise di segnare Fajardo Acevedo durante l'intero arco della sua vita e tutto ciò dovette riflettersi nelle sue commedie. Un rapido riepilogo della sua opera teatrale ci permette di evidenziale in quale misura il mondo cristiano è presente in essa. Egli scrisse ad esempio diverse commedie dedicate a santi, scritture che se vogliamo andrebbero inserite in un più amplio contesto agiografico. È il caso di El Divino Portugués, opera che ha come protagonista sant'Antonio da Padova o El Salomón de Mallorca, con protagonista Raimondo Lullo. C'è poi Origen de Nuestra Señora de las Angustias, commedia che celebra la patrona di Granada e che esalta l'azione soprannaturale dell'immagine sacra o La estrella de Europa y Fénix de Africa, dai contenuti molto simili. Anche dai titoli delle sue commedie perse s'intuisce l'importanza del tema cristiano: San Juan limosnero, el gran padre de los pobres; San Pascual Baylon; la pirma parte de La estrella de Europa y Fénix de Africa.

Nel 1675 compare nella Parte quaranta de comedias nuevas un testo teatrale di Fajardo Acevedo dal titolo Origen de Nuestra Señora de las Angustias y

\footnotetext{
26 «Lo poco que sabemos de su vida y certa tendencia a «viajar con la mente» [...] dejan adivinar a una persona sumergida en su tempo, estimulada por una curiosidad constante, como nos indican por ejemplo sus frecuentes cambios de profesión.» (Antonio FAJARDO Y ACEVEDO, Comedias, a cura di Diego SIMINI, Lecce 2001, p. 13).

${ }_{27}$ Per i problemi relativi ad una possibile biografia di Fajardo Acevedo: Ibidem, pp. 12-14.

28 Ibidem, p. 7.

29 Per la bibliografia di Fajardo Acevedo: Ibidem, pp. 15-29.
} 
revelión de los moriscos. Probabilmente l'occasione che fece da sfondo alla scrittura dell'opera fu l'inaugurazione della nuova facciata della cattedrale di Granada, così come viene presentata nella prima scena. È plausibile supporre che tra il 1672 e il 1673 Fajardo Acevedo avesse ripreso a viaggiare per la Spagna $^{30}$ e che magari proprio nel 1673, quando sappiamo con sicurezza che la quarantesima raccolta di comedias nuevas era già pronta e difficilmente l'autore doveva trovarsi a Madrid ${ }^{31}$, si trovasse a Granada, città in cui è ambientata la nostra commedia.

L'opera ha al centro del nucleo narrativo la vicenda della ribellione degli arabi nella città di Granada ${ }^{32}$. Dopo la presa di Granada molti arabi si erano convertiti. Nonostante questo, però, i procuratori della Corona non nascondevano l'inquietudine provata di fronte al problema del contenimento dei musulmani: queste paure portarono a una serie di forti imposizioni nei confronti degli arabi. Nel 1560 fu proibito a coloro che professavano la fede islamica di avere schiavi; nel 1562 furono disarmati tutti i mori valenziani e l'anno dopo toccò a quelli granadini: ad essi fu proibito di portare armi senza il permesso delle autorità militari. Nel 1564 fu impedito agli arabi di rifugiarsi nelle chiese (mezzo utilizzato per sottrarsi alla giurisdizione ordinaria). Le ultime e più dure azioni furono la proibizione della lingua araba in pubblico ed in privato, l'utilizzo di abiti che li distinguessero, la consegna di libri in lingua araba e l'obbligo di tenere aperte le case perché si potesse vigilare su di esse. Tutte queste disposizioni esasperarono i mori, i più temerari dei quali scapparono $\mathrm{e}$ si rifugiarono sulle montagne ${ }^{33}$. Uno di questi, Farax-ben-Farax, penetrò in Granada il 18 aprile del 1568, giorno di Pasqua, assieme ad un gruppo di ribelli, ma dovette fuggire a causa del mancato incontro con un altro gruppo di rivoluzionari, quelli dell'Albaicín. Ai mori rivoltosi si unì don Fernando de Córdoba y Valor, cavaliere cristiano scappato dalla prigione in cui era stato costretto a causa della sua cattiva condotta, il quale fu nominato re secondo il rito musulmano. Farax-ben-Farax si rese subito dopo autore di un eccidio di cristiani: in sei giorni circa seimila persone furono uccise dopo essere state torturate dal moro. Alla fine dello stesso anno, il 1568, don Fernando dovette, a causa dell'eccessiva crudeltà, destituire Farax-ben-Farax dal suo incarico. La lotta continuò duramente da entrambe le parti ma la pressione cristiana si fece sempre più forte fino a quando nel 1570 l'insurrezione era quasi completamente stata domata. Giovanni d'Austria, fratello di Filippo II, assunse il comando

\footnotetext{
30 Ibidem, p. 14.

31 Ibidem, p. 13.

${ }^{32} \mathrm{La}$ Spagna fu «scossa da uno sbarco dei maghrebini in Andalusia, seguito dalla rivolta dei moriscos di quella regione tra 1565 e 1570» (Franco CARDINI, Europa e Islam. Storia di un malinteso, Roma-Bari 1999, p. 236).

${ }^{33}$ Eduardo IBARRA Y RODRÍGUEZ, España bajo los Austrias, Barcelona 1955, pp. 210-216.

Poder y religión en la Hispania Medieval y Moderna Hispania Sacra 56 (2004)
} 
dell'impresa mentre alla fine dell'aprile del 1569 arrivarono dall'Algeria degli ausiliari in aiuto dei mori. Il 22 maggio del 1570 il re arabo si sottomise a Giovanni d'Austria e alla fine dello stesso anno i mori granadini furono deportati in Castiglia.

Parallelamente a questo episodio si sviluppa nella commedia di Fajardo y Acevedo un lungo elogio dell'immagine miracolosa, patrona di Granada, vera protagonista della commedia e che determinerà la sconfitta dei musulmani. La prima scena si apre sul frontespizio della chiesa di Nuestra Señora de las Angustias e con un coro di angeli che cantano in onore della Vergine. Subito dopo viene introdotto uno dei personaggi principali, Avenfarax, personificazione del demonio e rappresentante della brutalità dell'intera comunità dei musulmani. A metà del primo atto appare l'immagine della Madonna portata da due angeli in una cappella di Granada e lasciata li proprio per volere suo volere. Questa secondo quello che si deduce da quanto detto poco prima da Bustos (altro personaggio della commedia e «padre spirituale» della comunità granatina) sarebbe originaria di Toledo, città dalla quale era scomparsa. Avenfarax viene dipinto come superbo, crudele e sanguinolento, mentre escogita il piano della rivolta. Nel secondo atto continuano gli elogi rivolti all'immagine e l'episodio principale consiste nel tentativo di profanare la hermita nella quale è conservata l'immagine sacra da parte di Avenfarax, tentativo che fallisce grazie all'intervento degli angeli che proteggono «la casa de María» ${ }^{34}$. I cristiani avendo saputo da Doña María dell'immediata rivolta dei mori si preparano alla difesa e invocano la protezione della Vergine. Questa nel terzo atto appare in sogno a don Fernando e lo invita alla conversione mentre la scena principale dell'atto propone il discorso di Doña María a Juan de Austria, nel quale si raccomanda all'imperatore la difesa della città e della cristianità, confidando nell'aiuto divino della patrona di Granada. L'imperatore fa voto «a la soberana Virgen / de las Angustias.... ${ }^{35}$ di intervenire militarmente nella questione. Le forze ribelli di Fernando e Avenfarax si uniscono in battaglia ma basta la visione dell'effige della Virgen de las Angusties sullo stendardo imperiale per togliere le forze a Fernando, che si convertirà in punto di morte, e mettere in fuga i mori, mentre Avenfarax agonizzante ammette la vittoria della patrona di Granada. I cristiani con l'aiuto divino domano così la rivolta e l'immagine viene portata nella nuova cattedrale dove le viene concessa la proprietà del terreno circostante.

\footnotetext{
34 Antonio FAJARDo y ACEVEDo, «Origen de Nuestra Señora de las Angusties», in Comedias..., p. 170 , v. 1633.

35 Ibidem, p. 183, vv. 2603-2604.
} 


\section{IL PROTAGONISMO DELL'IMMAGINE.}

La protagonista della commedia Origen de Nuestra Señora de las Angustias è l'immagine della Vergine patrona di Granada. Si potrebbe obiettare che un'immagine non può essere la reale protagonista di un'opera ma solo un punto al quale fanno riferimento tutti gli episodi salienti come ad esempio la rivolta degli arabi e la conseguente intercessione della Vergine a contenimento di essa. Bisogna considerare, però, che la commedia è stata pensata in funzione di elogio dell'immagine e di celebrazione del suo patronato sulla città di Granada. Per questo motivo i riferimenti all'immagine della Vergine sono continui, ma non solo in questo si esaurisce il suo protagonismo nella commedia. L'immagine è infatti avvertita come reale agente nelle vicende delle città, come personaggio indipendente con una propria volontà che la porta, ad esempio, ad essere condotta e lasciata proprio a Granada, nella città da lei scelta. Nell'episodio dell'arrivo dell'immagine nella città portata da due angeli dalle sembianze umane di pellegrini, alla domanda di Bustos sul perché di quella venuta il primo angelo risponde: «Lo mandó Nuestra Señora». ${ }^{36}$ Questa forza autonoma richiama direttamente quanto già notato da Burke a proposito delle immagini sacre:

La posa del Cristo, della Vergine, o dei Santi, di solito frontale, con lo sguardo rivolto agli osservatori, incoraggia a considerare l'oggetto come se si trattasse di una persona. Leggende di icone cadute in mare e poi miracolosamente approdate sulla terra ferma, rinforzano l'espressione di una forza autonoma di queste immagini ${ }^{37}$.

Prova di questo rapporto diretto e «umano», tra osservatore ed oggetto osservato, è infatti l'equivoco che segue l'arrivo dell'immagine. Gli angeli vanno via e la lasciano nella piccola cappella dove erano poco prima giunti, coperta da un velo. L'immagine della Vergine, che è una statua incastonata in un telaio, provoca dei fraintendimenti per via della sua fisicità, tridimensionalità che occupa nello spazio scenico il posto che occuperebbe un qualsiasi altro personaggio. Bustos infatti non capisce subito che si tratta di una statua e le si rivolge come ad una donna:

Señora, el velo corred, que en parte seria estáis.

¡Responded! ¿Cómo no habláis?

(vv. 397-399)

36 Antonio Fajardo y Acevedo, «Origen de Nuestra Señora...»..., p. 154, v. 388.

37 Peter BURKE, Testimoni oculari, Roma 2002, p. 59.

Poder y religión en la Hispania Medieval y Moderna

Hispania Sacra 56 (2004) 
Egli non si accorge che si trova di fronte ad una statua fino a quando, dopo i numerosi inviti a parlare e a scoprirsi dal velo, l'immagine non rivela la sua vera essenza. Questo episodio è chiara metafora del fatto che l'immagine è presenza reale del prototipo che rappresenta ${ }^{38}$. In un saggio di Kitzinger, relativamente all'epoca post-giustinianea, lo studioso ricorda che molti scrittori di quel periodo «accarezzarono l'idea dell'immagine intesa come reale dimora della persona raffigurata ${ }^{39}$. Tra i personaggi della commedia (e presumibilmente nel suo pubblico) avviene quello che si verifica nella coscienza dei credenti in presenza delle reliquie di un santo. Queste vengono avvertite come presenza reale del santo, della persona cara $^{40}$, tanto che «si credeva che il santo in cielo fosse «presente» presso la sua tomba in terra» ${ }^{4}$. Se la presenza reale del santo è segnata nel caso delle reliquie dai fatti straordinari che avvengono in loro presenza ${ }^{42}$, allo stesso modo nella commedia di Fajardo la statua di Nuestra Señora de las Angustias agisce, opera, attua in maniera indipendente fatti meravigliosi (in questo modo, ad esempio, va interpretato lo spontaneo suonare delle campane allo scoprirsi del velo dell'immagine $)^{43}$, per proprio volere, come se effettivamente si trattasse di un personaggio a se stante, avente le stesse funzioni drammatiche e capacità decisionali degli altri personaggi. Prosperi come Brown hanno sottolineato il valore dato alle reliquie e alla loro presentia come concordia di una comunità ${ }^{44}$, all'importanza del fatto che esse fossero fisicamente presenti in una comunità; allo stesso modo nella comunità granadina rappresentata da Fajardo, l'immagine della Vergine viene ad assumere il ruolo di patronato, di concordia della comunità stessa:

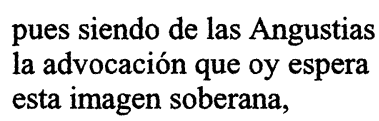

\footnotetext{
38 «Per le immagini [...] mi limito solo a richiamare la funzione strutturale di garanti, di pegni della presenza reale del referente» (Luigi CANETTI, Frammenti di eternità..., p. 115).

39 Ernst KITZINGER, Il culto delle immagini..., p. 99.

40 «in una reliquia si poteva pensare che la gelida anonimia dei resti umani fosse ancora piena della presenza della persona cara» (Peter BROWN, Il culto dei santi..., p. 19).

${ }^{41}$ Ibidem, p. 12.

42 «gli invasamenti e gli esorcismi che avevano luogo nelle grandi basiliche della Gallia cattolica, erano ritenuti l'unico segno inconfutabile della presentia in esse dei santi» (Ibidem, p. 124). «Le raffigurazioni del santo ne diffondono presentia e virus, consentendo di usufruire anche lontano dalla sua tomba degli stessi privilegi e delle stesse prodigiose facoltà salvifiche.» (Luciano SANGERMANO, «Il «santo sognato». Esperienze oniriche e guarigioni miracolose nell'agiografia francescana dei secoli XIII e XIV», in Quaderni storici, 38 (2003) n 112, p. 34).

43 Antonio FAJARDO Y ACEVEDO, Origen de Nuestra Señora..., p. 154, v. 404.

44 «l'esserci del santo era proprio la presenza fisica del suo corpo o di parti di esso.» (Adriano PROSPERI, «L'elemento storico nelle polemiche sulla santità», in Finzione e santità tra medioevo ed età moderna, a cura di Gabriella ZARRI, Torino 1991», p. 96).
}

Poder y religión en la Hispania Medieval y Moderna Hispania Sacra 56 (2004) 


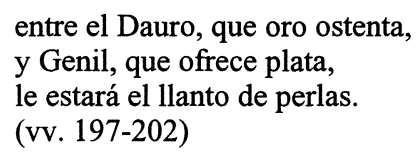

Dunque l'immagine benedice la comunità e la terra, privilegio peraltro riservato originariamente proprio alle reliquie dei santi. Questa funzione protettrice dell'immagine si tradurrà in un intervento diretto di questa a protezione della città allorquando Granada verrà scossa da una forte rivolta degli arabi.

\section{PIÙ UNICA CHE RARA: «ES LA PRIMERA QUE SE HIZO».}

Un dato che risulta subito evidente nelle comedias che hanno come protagonista un'immagine miracolosa, è una presunta unicità di questa, unicità che corrisponderebbe alla ragione ultima della sua azione miracolosa. Anche Fajardo Acevedo in Origen de Nuestra Señora de las Angustias non dimentica di puntualizzare questa proprietà. In maniera piuttosto originale la particolarità dell'immagine protagonista della sua commedia non andrebbe cercata in una storia dai caratteri leggendari ${ }^{45}$, bensì nella materia da cui essa stessa è formata. Nel racconto di Doña María a proposito dell'origine dell'immagine ${ }^{46}$ viene chiarito che non si tratta di una pittura né di una scultura, ma di una statua incastonata in un telaio:

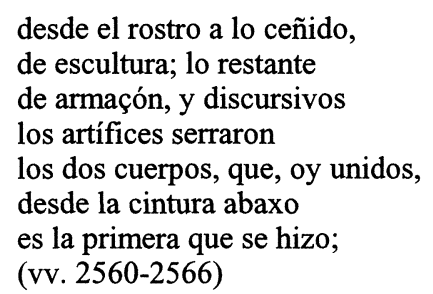

due corpi dunque inglobati in un unico nucleo; l'importanza dell'immagine starebbe non nella sua origine leggendaria ma nella sua duplice natura così densa di significati:

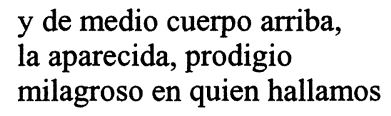

${ }^{45}$ Il riferimento è alla vastissima tradizione che si riferisce alle immagini acheropite come nel caso del dramma di Calderón.

46 Antonio FAJARDO Y ACEVEDO, «Origen de Nuestra Señora...»..., pp. 182-183, vv. 2505-2574.

Poder y religión en la Hispania Medieval y Moderna

Hispania Sacra 56 (2004) 
un concepto en dos sentidos, (vv. 2567-2570)

Il v. 2570 è metafora che rimanda al Cristo e in questo sta il significato dell'immagine e delle due parti impiegate per la sua realizzazione. La «escultura» e l'«armaçón» richiamano quel "concepto en dos sentidos», la natura umana e divina del Salvatore. Già nel primo atto era stata presentata l'immagine della Vergine; la sua origine inserita nel mitico episodio della perdita di un'immagine a Toledo ${ }^{47}$ si ricongiunge ora con quella della nuova statua venerata a Granada. Il passaggio di «consegne» dall'immagine originale a quella «nueva» viene chiarito poco prima del lungo discorso di Doña María da lei stessa: l'antica era di «talla»e il vestito «de negro y de oro». ${ }^{48}$ La puntualizzazione relativa all'immagine originale pone la stessa, l'originale cioè e di conseguenza la «nueva», in un tempo lontano e mitico ${ }^{49}$ e la sostituzione di quella nuova corrisponde di fatto ad un trasferimento diretto di poteri. Su questo punto insiste Palumbo quando dice che una presunta santità (e vada bene questo sostantivo in riferimento alle icone miracolose) deve appoggiarsi ad una "santità antica», e cioè: «antichità di una tradizione narrativa»" ${ }^{50}$. In pratica andrebbe rintracciata nel tempo leggendario la capacità taumaturgica dell'immagine, elemento che risulta evidente anche dalle argomentazioni di Doña María sull'origine della statua di Nuestra Señora de las Angustias.

\section{FERVORE ICONOCLASTA.}

Sono molti nell'opera i rapporti tra la comunità granadina e i primi cristiani, così come tra $\mathrm{i}$ protestanti e gli infedeli. In realtà più che parlare dei ribelli dovremmo da subito puntualizzare che i riferimenti alle distruzioni delle immagini, ed particolarmente di quella di Nuestra Señora de las Angustias, sono fatti che riguardano soltanto le intenzioni di Avenfarax, tanto è vero che i suoi stessi seguaci non intendono fino in fondo i piani iconoclasti del demonio. ${ }^{51}$

47 «De las Angustias perfecta / una imagen he perdido / a Toledo, y no ha venido» (Ibidem, p. 154, vv 373-375).

48 Ibidem, p. 183, vv. 2557-2559.

49 «L'immagine possiede la sua forza taumaturgica proprio perché costituisce l'unico, tangibile trait-d'union del rapporto tra il tempo magico e lontano del miracolo e il tempo reale e concreto della vita vissuta.» Genoveffa PALUMBO, «Sante immagini e santità immaginata: una simulazione «familiarem)", in Finzione e santità..., p. 157).

50 Ibidem, p. 148.

51 In realtà c'è un episodio in cui la furia iconoclasta dei musulmani appare evidente. Nella storia che Doña María racconta a Zoraya circa l'episodio della rivolta degli arabi a Villa de Guecíjar, durante la quale venne martoriato suo padre, tra le altre cose l'attenzione punta sull'incursione di questi nei 
Durante il primo atto, nel monologo del personaggio diabolico, viene da subito sottolineata la fusione tra i due impegni dei ribelli: distruzione dell'effige della Vergine e rivolta degli arabi. Avenfarax dichiara di voler combattere contro la fede cristiana, rovinando templi e sottomettendo sacerdoti:

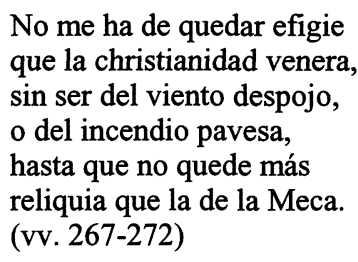

Gli intenti del demonio sono chiari. Non deve essere salvata nessuna effige che la cristianità possa venerare. Qui il riferimento agli iconoclasti dei primi secoli del cristianesimo si fa evidente, ma ancor più chiaro appare la vicinanza di vedute di questi a quella dei protestanti. Impossibile non cogliere il parallelo tra le intenzioni di Avenfarax e l'azione vandalica degli ugonotti di distruzione d'immagini e reliquie ${ }^{52}$. Il tema della distruzione delle immagini sta alla base delle rivendicazioni del demonio e ne determina le azioni ribelli. La sua ferocia iconoclasta diventa il simbolo della rivolta, l'obbiettivo principale la distruzione delle immagini:

\section{No avrá imagen que no sea hollada de los pies nostros. (vv. 795-796)}

Tuttavia il disegno diabolico resta segreto. Il resto dei ribelli sembrano infatti esclusi dal piano oscuro di Avenfarax; essi chiedono che venga spezzato il giogo che li tiene assoggettati alla fede cattolica ma non esprimono particolare fervore iconoclasta. Nell'episodio centrale del secondo atto, il tentativo di entrare nella «hermita», dimora dell'immagine della Vergine, Avenfarax si arrischia in uno sforzo improbabile di profanazione che non viene inteso a fondo nemmeno dal suo braccio destro Daúd. Questi non intende perché rischiare tanto nel futile

\footnotetext{
templi cristiani: «Arrojáronse a los templos / con ossadía resuelta, / robaron los ornamentos, / haziendo, por mayor befa, / de los frontales vestidos, / y con altiva sobervia / deribaron los altares, / los retablos hazen pieças, y en las imágenes santas / toda su cólera vengan.» (Antonio FAJARDO Y ACEVEDO, «Origen de Nuestra Señora...»..., p. 154, vv. 1715-1724).

52 «La destruction des reliques (comme celle des images), semble donc bien avoir eu un sens symbolique fort, Il s'agisait, en les détruisant, de démontrer l'existence d'une supercherie et de purifier un espace» (Alain JOBLIN, «L'attitude des protestants face aux reliques», in Les reliques. Objets, cultes, symboles. Actes du colloque international de l'Université du Littoral-Côte d'Opale, ed par Edina BOZOKY e Anne-Marie HELVETIUS, Brepols 1999, p 135).
}

Poder y religión en la Hispania Medieval y Moderna

Hispania Sacra 56 (2004) 
tentativo di profanare una cappella: ciò che interessa i musulmani, in fondo, non è che la rivolta finale:

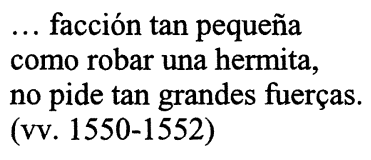

Ma finalmente Avenfarax rivela le ragioni del piano suo diabolico, del desiderio di profanare la «hermita»:

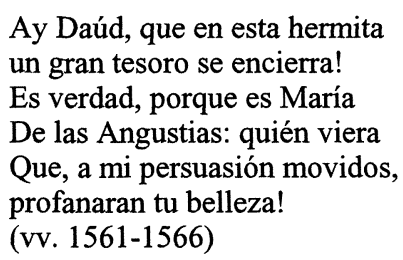

Il tentativo fallisce. Gli angeli intervengono e cacciano via Avenfarax che fugge riconoscendo la superiorità delle forze celesti.

\section{PALlADio DELLA BATTAGLiA.}

In uno studio di Sendler sull'icona leggiamo:

Per comprendere il carattere specifico dell'immagine sacra a Bisanzio, dell'icona, non bisogna sottovalutare un fatto - storico o leggendario che sia qui non importa- legato strettamente alla conversione di Costantino: prima della battaglia di Ponte Milvio, Costantino vide una croce fiammeggiante con le parole: «con questo segno vincerai» (in hoc signo vinces). Durante la notte, gli apparve Cristo, che teneva in mano la stessa immagine che aveva vista in cielo, e gli comandò di metterla subito sullo stendardo che doveva precedere i combattimenti nella battaglia: questo stendardo o bandiera era il «labaro» che lo condusse alla vittoria ${ }^{53}$.

Che l'ostensione di immagini ritenute in qualche modo di origine divina precedesse le battaglie a fini protettrici era fatto normale, così come dai primi secoli cristiani si iniziò a credere che queste scendevano dai cieli per aiutare gli eserciti a sbaragliare i nemici in nome della fede. Nell'episodio citato da

53 Egon SENDLER, L'icona, immagine dell'invisibile..., p. 20; L'episodio del sogno di Costantino e le sue diverse versioni leggendarie sono raccontato anche da Jacopo da Varagine nella Leggenda Aurea (Jacopo da VARAGINE, Leggenda aurea, Firenze 1990, pp. 306-315).

Poder y religión en la Hispania Medieval y Moderna Hispania Sacra 56 (2004) 
Sendler, ci sono tutti gli elementi leggendari dell'immagine palladio: la visione, il sogno, il segno. Che si tratti effettivamente di storia o leggenda, appare chiaro dalle parole di Sendler che poco importa. Che l'apparizione si fosse realmente verificata o no, in effetti, non doveva cambiare di molto le cose: nelle coscienze dei soldati doveva accendersi la fiamma della battaglia, e questo era la cosa importante. Sogno o visione che sia stata, comunque, l'esperienza onirica serviva a preannunciare l'azione mediatrice del Salvatore: la sua apparizione a Costantino annunciava l'imminente manifestarsi divino nella battaglia di Ponte Milvio. Nella prima visione l'imperatore vede una croce fiammeggiante, il segno della vittoria. Nel sogno, o apparizione notturna, è il Cristo a tenere la croce ed è quest'immagine che verrà poi riproposta sullo stendardo imperiale. Chiaramente non si tratta di una semplice figura, ma del Cristo stesso che scende in campo e precede le truppe. Rincuorati da questa presenza eccezionale siamo sicuri che $\mathrm{i}$ soldati dovettero combattere con un fervore che altrimenti sarebbe stato difficile ottenere.

Costantino non fu il primo a esibire un oggetto in qualche modo «non umano» in funzione apotropaica e di palladio durante una battaglia. Ricordiamo ad esempio la leggenda del re Abgar e della sua presunta corrispondenza con Gesùs $^{5}$. Secondo le parole della pellegrina Egeria il re avrebbe usato la lettera inviatagli da Gesù per proteggere la città e le sue caratteristiche positive intrinseche non tardarono a manifestarsi: pare infatti che in seguito all'accerchiamento di Edessa da parte dei persiani, dopo aver pregato il Signore, il re Abgar alzò al cielo la lettera sacra e la mostrò ai nemici; subito il cielo si oscurò e a questo seguirono altri miracoli che alla fine misero i persiani in fuga ${ }^{55}$. Sappiamo anche che nei primi secoli cristiani Basilio di Cesarea, come tanti altri vescovi, condusse un'instancabile attività di ricerca di reliquie che potessero in qualche modo fungere da palladio per l'intera regione e patrocinare in questo modo le Chiese locali ${ }^{56}$. Ma ciò non avveniva solo in Oriente. In Francia la devozione per san Martino di Tours riservò manifestazioni molto simili a quelle viste con Basilio di Cesarea: «Cette dévotion à saint Martin dans la dynastie explique aussi que la chape du saint soit devenue sinon le drapeau de l'armée royale, en tout cas une relique-palladium sur laquelle se font les serments solennels» ${ }^{57}$. Abbiamo in questo modo chiaro il fatto che non importava che l'oggetto sacro

\footnotetext{
54 Secondo questa leggenda Re Abgar avrebbe invitato nel suo regno Gesù, ma questi si limito a scrivergli una lettera.

55 EgERIA, Pellegrinaggio in Terra Santa, Roma 1985, pp. 109-111.

56 BASIllo DI CESAREA, I martiri. Panegirici per Giulitta, Gordio, 40 soldati di Sebaste, Mamante, Roma 1999, p. 8.

${ }^{57}$ Etienne DELARUELLE, «La spiritualità des pèlerinage a saint-Martin de Tours du $\mathrm{V}^{\mathrm{e}}$ au $\mathrm{X}^{\mathrm{e}}$ siècle», in Pellegrinaggi e culto dei santi in Europa fino alla $I^{a}$ crociata, IV Convegno del Centro di studi sulla spiritualità medievale. 8-11 ottobre 1961, Todi 1963, pp. 212-213.
}

Poder y religión en la Hispania Medieval y Moderna Hispania Sacra 56 (2004) 
fosse un'immagine su di uno stendardo, una reliquia o addirittura una lettera, come nel caso della leggenda di Edessa, ma la sua origine acheropita, divina, sacra, il fatto che fosse una testimonianza della presenza e dell'aiuto soprannaturale, dell'intercessione della divinità in fatti squisitamente terreni.

La pratica di utilizzare le immagini come palladio in difesa delle città e degli eserciti divenne una delle principali manifestazioni del culto delle immagini dell'Impero bizantino ${ }^{58}$ e si diffuse particolarmente durante il periodo giustinianeo. Nel 626, in una Costantinopoli attaccata dai barbari, un'immagine acheropita del Cristo «à côté de la relique du maphorion de la Vierge, est portée sur les murs de Constantinople pour écarter de la ville un assaut des barbares ${ }^{59}$. Sempre nella stessa città, durante l'assedio degli arabi del 717, attorno alle mura sfilò un'immagine, questa volta quella della Vergine, assieme alle reliquie della santa Croce $^{60}$. Queste funsero da palladio anche nel 1044, allorquando un frammento della Vera Croce venne portato in battaglia dall'imperatore Enrico III contro Abu Samuel che aveva usurpato il trono in Ungheria ${ }^{61}$. Tra l'altro le reliquie della Vera Croce erano state anche le insegne militari di Federico II Hohenstaufen ${ }^{62}$ ed avevano portato alla vittoria nel 955 Ottone I nella battaglia di Lechfeld ${ }^{63}$. Ancora, Grabar ricorda che «les icones tiendront toujours une place marquée, et Jean Tsimiscès, au $\mathrm{X}$ siècle, accordera les honneurs du triomphe militaire à une icone de la Vierge $)^{64}$. Tutti esempi, questi, della diffusione di una nuova pratica che da Oriente si amplificava e si espandeva verso Occidente. Abbiamo, in verità, anche testimonianza di immagini sacre usate in funzione apotropaica nell'Europa occidentale a partire da molto presto. Le notizie più note sono quelle relative alla Salus Populi Romani, famosa acheropita dipinta secondo la tradizione da S. Luca e conservata oggi nella chiesa di S. Maria Maggiore a Roma, ma non solo. Un'altra importante acheropita, l'immagine del Cristo stesso, era custodita nel Sancta Sanctorum, scrigno delle più importanti reliquie venerate in Occidente. Quest'icona «alle origini, al tempo di Stefano II, fu palladio, immagine di pubblica salvezza» ${ }^{65}$. Le ostensioni di queste due immagini, inoltre, dovevano avere un particolare gusto

58 Ernst KITZINGER, Il culto delle immagini, cit., p. 40.

59 André GRABAR, Martyrium. Iconographie, cit., p. 352.

60 Emst KITZINGER, Il culto delle immagini, cit., p. 43; A. Frolow, La reliquie de la Vraie Croix. Recherches sur le développement d'un culte, Institut Français d' Ėtudes Byzantines, Paris, 1961, p. 189.

${ }^{61}$ A. Frolow, La reliquie de la Vraie CroiX. Recherches sur le développement d'un culte, Paris 1961, p. 271.

62 Ibidem, p. 376

63 Ibidem, p. 450

64 André GRABAR, Martyrium. Iconographie, cit., p. 352.

65 Enrico PARLATO, «La processione di Ferragosto e l'acheropita del Sancta Sanctorum», in $I l$ volto di Cristo, cit., p. 52. 
teatrale ${ }^{66}$ : a Ferragosto si muoveva un'importante processione per le vie della città. L'acheropita della Sancta Sanctorum partiva dal Laterano durante la notte di quel giorno e all'alba raggiungeva la chiesa di S. Maria Maggiore dove si riuniva con Maria, sua madre, la Salus, «l'acheropita, cioè Cristo stesso, incontrava $[\ldots]$ la Madonna in persona» ${ }^{67}$. La più antica notizia sulla Salus riferisce di una processione di questa nel VI secolo per «chiedere la cessazione della peste ${ }^{68}$, testimonianza ancora una volta del patrocinio di questo oggetti sacri sulla comunità dei fedeli.

È ora evidente che «la patrona de Granada ${ }^{69}$, l'immagine di Nuestra Señora de las Angustias, deve esercitate il suo patronato anche in funzione apotropaica. Iniziamo col dire che quanto accennato circa la credenza che le queste immagini scendevano dal cielo per aiutare e proteggere le comunità cristiane, viene riproposto anche nella commedia di Fajardo y Acevedo:

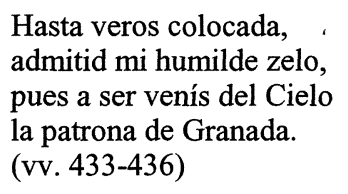

ed infatti alla fine dei primi scontri viene palesata la funzione protettrice dell'immagine da un nobile personaggio della commedia, il marqués de Mondéjar:

pues nos ha dado este triunfo

la patrona de Granada.

(vv. 2065-2066)

Bisogna tuttavia aspettare il terzo atto della commedia perché il potere miracoloso dell'immagine si manifesti apertamente nella questione della rivolta dei musulmani, ed è ancora una volta il colloquio di Doña María con l'imperatore Juan de Austria ad essere centrale nello sviluppo del tema. Tutto il racconto sull'origine dell'immagine è funzionale all'invito ad usare la stessa per proteggere i cristiani nella battaglia, ed infatti l'imperatore fa voto alla Vergine e promette d'intervenire militarmente nella questione, in un'unione di forze umane e divine. Simbolo di questa nuova alleanza diventa lo stendardo imperiale sul quale comparirà l'effige della Vergine, l'immagine di Nuestra

66 Silvia CARANDINI, Teatro e spettacolo nel Seicento, Roma-Bari 1990, p. 56.

67 Enrico PARLATO, «La processione di Ferragosto...»..., p. 51.

68 Genoveffa PALUMBO, Giubileo giubilei. Pellegrini e pellegrine, riti, santi, immagini per una storia dei sacri itinerari, Roma 1999..., p. 262.

69 Antonio FAJARDO Y ACEVEDO, «Origen de Nuestra Señora...»..., p. 154, v. 435.

Poder y religión en la Hispania Medieval y Moderna Hispania Sacra 56 (2004) 
Señora de las Angustias ${ }^{70}$. Difficile non notare l'incredibile somiglianza della nostra vicenda con la leggendaria visione della croce di Costantino e la successiva sua vittoria. Qui come lì l'intervento divino s'inserisce in una vicenda umana, e in entrambi i casi lo stendardo imperiale con l'effige sacra porta alla vittoria gli eserciti. Apparentemente mancherebbe solo il sogno notturno, premonitore della vittoria dei cristiani. In realtà il sogno c'è ma non è l'imperatore a farlo, né un eroe cristiano coinvolto nella battaglia, ma un musulmano: don Fernando. Questi racconta di un'apparizione della Vergine de las Angustias $^{71}$ che lo invita a convertirsi:

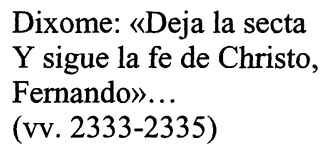

L'episodio, apparentemente superfluo, in realtà è centrale nella risoluzione della questione del patrocinio divino. Il sogno di Fernando è un sogno premonitore: esso annuncia un miracolo, testimonia l'immediato intervento della Vergine. Esattamente come nella leggenda di Costantino, l'esperienza visionaria è ciò che introduce il miracolo vero e proprio. In uno scritto di Sangermano, tutto quanto abbiamo detto viene riassunto nel seguente modo:

Quando invece è il santo ad essere sognato, l'evento diventa prova della capacità di intercessione degli eroi della fede, legandosi quasi sempre ad un intervento straordinario finalizzato ad alleviare le sofferenze o alla riparazione di una colpa. In questo caso il sogno, anche quando non è percepito ed interpretato quale miracolo, si inserisce in un contesto di manifestazione eccezionale: a questo segue infatti $[. .$.$] un evento sopranna-$ turale ${ }^{72}$.

Sangermano si riferisce a casi in cui sono i santi ad essere sognati; nell'esperienza di don Fernando è l'apparizione-sogno di Maria a garantire $l^{\prime}$ 'evento soprannaturale ${ }^{73}$. Più tardi lo stesso don Fernando rivedrà l'immagine della Vergine sullo stendardo imperiale durante la battaglia. Non avrà le forze di opporsi alla potenza divina e si convertirà poco prima di morire sul campo. ${ }^{74}$ Poco dopo Juan de Austria fisserà sulle mura lo stendardo, la Vergine, monito

\footnotetext{
70 Ibidem, p. 184, vv. 2671-2678.

71 Ibidem, p. 180 . vv. 2318-2340.

72 Luciano SANGERMANO, «Il «santo sognato»...»..., p. 32.

73 Per il rapporto tra sogno e visione vedi Aline ROUSSELLE, «Miracoli e persecuzione: assenza e presenza», in Miracoli. Dai segni alla storia , a cura di Sofia BOESCH GAJANO e Marilena MODICA, Roma 2000.

74 Antonio FAJARDo Y ACEVEDO, «Origen de Nuestra Señora...»»..., p. 154, vv. 2917-2944.
}

Poder y religión en la Hispania Medieval y Moderna Hispania Sacra 56 (2004) 
contro gli infedeli. Questi scapperanno e i cristiani vinceranno grazie all'intervento di Nuestra Señora de las Angustias. La vicenda della rivolta dei mori e del miracolo dell'immagine della Vergine, ci riportano dove siamo partiti, ossia alle considerazioni di Sendler:

\footnotetext{
Nel secolo VII, sul drappo attaccato all'asta del labaro, figura l'immagine di Cristo «non fatta da mano d'uomo». Nel 622, l'imperatore Eraclio porta lui stesso quest'immagine e la mostra alle truppe prima della battaglia contro i persiani. La funzione di quest'immagine, data agli uomini miracolosamente, è di protezione, di vittoria sul nemico, su ogni nemico, cioè sul male 75 .
}

\section{FRANCISCO DE ROJAS ZORRILLA. NUESTRA SEÑORA DE ATOCHA.}

Nonostante Nuestra Señora de Atocha sia una commedia considerata da una certa critica «minore» rispetto alle grandi opere di Rojas Zorilla, va detto che proprio questi «heróicos despropósitos», cioè alcune commedie religiose come El Profeta Mahoma, Los trabajos de Tobías e appunto Nuestra Señora de Atocha, avrebbero accresciuto la fama del poeta nell'epoca in cui scriveva ${ }^{76}$. La commedia che esalta l'immagine della Vergine di Atocha venerata a Madrid fu pubblicata dallo stesso autore nella Parte Segunda delle sue commedie nel 1645. L'opera prevede i due classici schieramenti etno-religiosi dei cristiani spagnoli e degli arabi musulmani nell'ambito della leggendaria lotta di Riconquista. Il primo atto si apre con la scena in cui Rosa, eroina mora, giura di vendicare il fratello ucciso per mano cristiana. Nel campo arabo sono legati Limonada (gracioso) e don Fernando, gentiluomo cristiano. Di quest'ultimo Rosa subisce il fascino e per farsi rivelare particolari della sua vita libera Limonada il quale le confida che il suo signore è innamorato di una «morena». A questo punto è Fernando stesso che confessa quali sono i due amori della sua vita: si tratta della Vergine di Atocha e di Leonor, dama di corte. Fernando nel tentativo di mostrare un ritratto della dama amata a Rosa si sbaglia e le da una pittura della Vergine. Quando cercherà di riprenderla Rosa glielo impedirà. Alla fine sarà lasciato libero di andare dalla sua amata «humana» $\mathrm{e}$ s'impegnerà a tornare entro sette giorni per riscattare la pittura di Leonor tenuta da Rosa come «ostaggio» e data in cambio della ben più preziosa immagine della Vergine. La scena cambia e ci ritroviamo alla presenza di Leonor ed Elvira, sua sorella. Entra Gracián, il padre delle due, e legge una lettera inviatagli

75 Egon SENDLER, L'icona, immagine dell'invisibile..., p. 20.

76 Ramón de MESONERO ROMANOS, «Apuntes biográficos, bibliográficos y críticos», in Francisco de Rojas ZORRILla, Comedias escogidas, a cura di Ramón de MESONERO ROMANOS, Madrid 1952, p. VI.

Poder y religión en la Hispania Medieval y Moderna Hispania Sacra 56 (2004) 
dal re di Castiglia Alfonso. Le due dame sono in età da matrimonio cosicché Gracián si risolve nel dare in sposa Leonor a García, nobile antagonista di Fernando, mentre a questi Elvira, la più giovane delle due, quella di cui egli stesso aveva chiesto la mano. Leonor, anch'essa innamorata di Fernando, si dimostra delusa dalla richiesta del suo amato, ma presto viene scoperto l'equivoco: Fernando aveva chiesto in sposa la figlia più giovane convinto che questa fosse Leonor. La promessa è ormai fatta ma Gracián s'impegna segretamente con entrambi i pretendenti a dar loro in sposa l'ambita Leonor. L'atto si conclude con il desiderio di Gracián di ritrovare la scomparsa immagine della Vergine di Atocha. Nel secondo atto viene presentato Celin, fratello di Rosa, valoroso moro che combatterà per vendicare Aben-Jucef, fratello dei due. Celin torna vittorioso da alcune campagne: ha saccheggiato 24 villaggi e profanato 20 santuari d'immagini della Vergine. La scena cambia. Di notte García e Fernando vengono alle armi per rivendicare Leonor, ma questa entra in scena e riesce a placare l'ira dei due. Leonor racconta la leggenda della Vergine di Atocha ed invita i due a ricercare l'immagine scomparsa insieme a lei e al padre Gracián. Mentre ventimila arabi si avvicinano a Madrid per metterla sotto assedio, i cristiani cercano l'immagine persa e la ritrovano miracolosamente sull'altura dell'Atochar. I mori intanto arrivano alle mura di Madrid. Siamo nel terzo ed ultimo atto della commedia. Celin mostra il ritratto di Leonor, l'immagine che Fernando ha lasciato in mano di Rosa e che non è tornato a rivendicare. Ora però il cristiano scende sul campo di battaglia per riprendersi l'effige della dama amata, effigie rivendicata nel frattempo anche da García, eterno antagonista di Fernando. Nel frattempo Gracián parlando con le figlie le sprona a lottare ma Elvira si rifiuta di combattere sapendo di andare incontro a sicura morte. Preferisce morire sull'altare dedicato all'immagine della Vergine ritrovata e così la risoluzione di Gracián è tremenda. Egli è braccato dagli arabi e non vede scampo per le figlie: decide di uccidere le figlie e lo fa proprio sull'altare della Vergine. La battaglia però è vinta dai cristiani, grazie all'ormai classico intervento della Vergine Maria. Fernando incontra Rosa e Celin. Egli ha un debito con la mora ed ora può saldarlo: li lascia andare e loro liberi fuggono. Sulla commedia, però, grava l'ombra dell'assasinio di Elvira e Leonor. Fernando e García non si spiegano il perché di quel folle gesto quand'ecco che l'ultima scena vedrà le due dame inginocchiate davanti all'altare della Vergine. Sulle loro gole ci sono due segni, ma sono vive: quest'ultimo miracolo chiude la commedia di Nuestra Señora de Atocha. 
NICODEMO, SAN LUCA, GLI APOSTOLI. L'ORIGINE DELL'IMMAGINE.

Il racconto dell'origine dell'immagine di Atocha è affidato a don Fernando. La leggenda è molto interessante perché inserisce nel nucleo narrativo come protagonisti Nicodemo e san Luca. Nicodemo è il personaggio biblico che aiutò a scendere dalla croce il Cristo e con Giuseppe d'Arimatea lo portò al sepolcro. In seguito gli asciugò con un lenzuolo (la Sindone) il sudore:

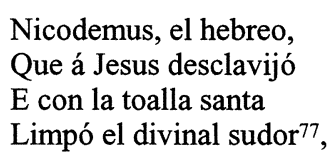

C'è relazione tra la Deposizione e la Sindone: tradizionalmente Nicodemo avrebbe intagliato un crocifisso direttamente sull'originale essendo stato l'ultimo a vedere Cristo morto sulla croce, il primo crocifisso mai scolpito e più somigliante al prototipo rappresentante. Uno dei miracoli avvenuti attorno al crocifisso spiega meglio che l'immagine che fece da modello alla scultura di Nicodemo fu proprio il lenzuolo che avvolse il Cristo disceso dalla croce. ${ }^{78}$ Tale crocifisso, secondo la tradizione, sarebbe stato poi terminato da un angelo. Si tratta del Volto Santo che dopo tutta una serie di vicissitudini giunse a Lucca nel $742^{79}$. Nella commedia di Rojas y Zorilla Nicodemo è invece l'artefice dell'immagine della Vergine di Atocha:

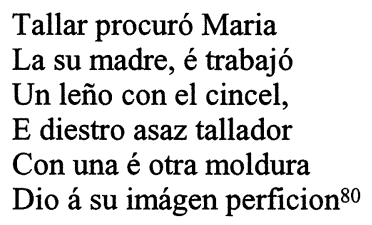

Il tradizionale scultore del primo crocifisso, quindi, diventa in Nuestra Señora de Atocha l'artefice della statua della Vergine. Ma la leggenda non termina qui. Viene inserita in essa un altro importante personaggio: san Luca l'evangelista. Questi avrebbe in un secondo momento operato sull'immagine della Virgen de Atocha e le avrebbe dipinto il viso:

\footnotetext{
77 Francisco de ROJAS ZORRILlA, «Nuestra Señora de Atocha», in Comedias escogidas, a cura di Ramón de MESONERO ROMANOS..., p. 472.

78 Genoveffa PALUMBO, «Immagini e devozione...»..., p. 198.

79 Michele Camillo FerRARI, «Il Volto Santo di Lucca», in Il volto di Cristo..., p. 253.

${ }^{80}$ Francisco de ROJAS ZORRILlA, «Nuestra Señora de Atocha»..., p. 472.

Poder y religión en la Hispania Medieval y Moderna

Hispania Sacra 56 (2004)
} 


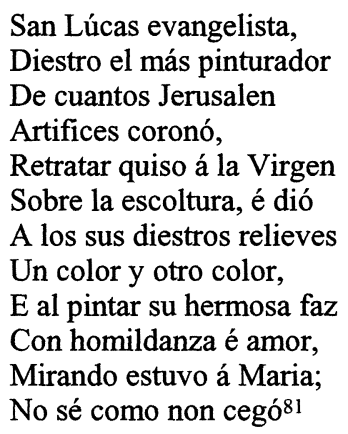

Il dipinto di san Luca sarebbe quindi stato realizzato «dal vero», sarebbe cioè stato eseguito non solo mentre la Vergine era ancora viva, ma addirittura con la complicità di Maria stessa che avrebbe posato per san Luca. Non solo: «Si diceva, inoltre, che egli non si era limitato ad un solo esemplare ma ne aveva eseguiti diversi e li aveva anche mostrati alla Madonna ricevendo la sua approvazione $\rangle^{82}$. La maggior parte delle fonti relative alle presunte pitture di san Luca appartengono al periodo iconoclasta e a quello successivo. Un tale argomento infatti servì più che altro ai difensori delle immagini. Tuttavia la prima fonte è una testimonianza di Teodoro il Lettore. Questi riferisce nello scritto di un'icona della Vergine dipinta dall'evangelista appartenente all'imperatrice Eudocia e inviata da questa a Pulchieria ${ }^{83}$. Altri riferiscono di «un'immagine della Madonna venerata a Costantinopoli nel monastero nominato «Nuova Gerusalemme»: l'Hodoghitria» ${ }^{84}$ Un'altra importante icona attribuita alla mano del maestro san Luca è la Salus Populi Romani, icona conservata a Roma nella chiesa di Santa Maria Maggiore ${ }^{85}$. Occorre ancora ricordare la venerazione legata ad una celebre icona, l'Iconavetere della Madonna, l'immagine cosiddetta del Sette Veli (sette furono i veli in cui fu avvolta e nascosta all'alba delle invasioni barbariche) venerata a Foggia e attribuita a san Luca. Quest'icona divenne straordinariamente famosa nel Basso Medioevo tanto che Alfonso X il Saggio nelle Cantigas de Santa Maria riferisce di un episodio miracoloso acca-

81 Idem.

82 Genoveffa PALUMBO, «Immagini e devozione...»..., p. 189. Nella nota n. 24 della stessa pagina leggiamo: «erano solo sette, come si ritrovava nei Mirabilia, le immagini che si disputavano l'onore di essere di mano di san Luca, e ben quattro di queste si voleva che fossero a Roma, in realtà, pare che se ne possano contare ben 600 ».

83 Idem.

${ }^{84}$ Idem. Anche Grabar nel Martirium, fa riferimento all'Odigitria: «Un autre groupe d'icones miraculeuses des plus importantes, dont l'Odiguitria (pl. LXIII, 4), sont attribuées à l'évangéliste saint Luc et rangées ainsi parmi œuvres d'inspiration divine» (André GRABAR, Martyrium. Iconographie..., p. 348).

85 Genoveffa PaLumBo, Giubileo giubilei..., p. 261-265.

Poder y religión en la Hispania Medieval y Moderna Hispania Sacra 56 (2004) 
duto in prossimità di essa ${ }^{86}$. Maria Andarolo accenna al Testamento di Tivoli del 1029 in cui si fa riferimento ad un'immagine «semiacheropita» in cui il disegno sarebbe stato realizzato da san Luca mentre il dipinto, la stesura cioè dei colori, sarebbe stata opera degli angeli ${ }^{87}$. Anche la Repubblica di Venezia vantava un'immagine della Vergine compiuta dall'evangelista. Quest'icona sarebbe stata trafugata dai veneziani da Costantinopoli nel Duecento ${ }^{88}$. Nel santuario di Montevergine pure si venerava un'icona dipinta dall'evangelista e si dice anche che il velo dell'immagine si alzasse misteriosamente ogni venerdi ${ }^{89}$. Ma la devozione verso le immagini presunte di san Luca non fu un fatto relativo alla sola area occidentale dell'Europa: un «terzo tipo di Madonna attribuito a san Luca, e Madonna detta in Russia di Vladimir, [era] considerata dalla devozione russa opera dello stesso san Luca» ${ }^{90}$. L'argomento che queste immagini offrivano era quello di una sorta di legittimità della loro venerazione. Nonostante l'approvazione della stessa Vergine però, il dipinto di san Luca non potrà mai eguagliare l'archetipo:

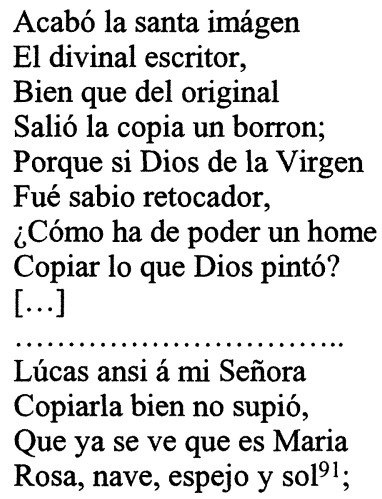

Una volta finita, l'immagine di Atocha appartenne a san Pietro che la portò da Gerusalemme ad Antiochia:

\footnotetext{
${ }^{86}$ La cantiga è la numero 136. Esta è como en terra de Pulla, / en hũa vila que á nome Foja, / jogava hũa moller os dadod con outras conpannas / ant' hũa eigreja; e porque perdeu, / lançou hũa pedra que déss'ao menỹo / de omage de Santa Maria, / e ela alçou o braço e recebeu o colbe. (Carlo BERETTA (a cura di), Miracoli della Vergine. Testi volgari medievali, Torino 1990, p. 892).

87 Maria ANDAROLO, «L'acheropita in ombra del Laterano»..., pp. 43-45.

88 Peter BURKE, Testimoni oculari..., p. 60.

${ }^{89}$ Genoveffa PALUMBO, « Sante immagini...»..., pp. 158-159.

90 Anna Maria PRASTARO, Dal Damasceno e il Concilio di Nicea II (787) alla «Vita» di Cirillo e Metodio (IX sec.), Lecce 1989, p. 64.

${ }^{91}$ Francisco de ROJAS ZORRILlA, «Nuestra Señora de Atocha»..., p. 472.

Poder y religión en la Hispania Medieval y Moderna

Hispania Sacra 56 (2004)
} 
De Jerusalen á Antióquia
Con esta imágen partió
${ }^{2}$

Pietro giunse quindi in Spagna con gli altri apostoli e lasciò l'immagine a Madrid:

\author{
Dempues vino Pedro á España, \\ E caduca tradicion \\ Fabla que en la playa antigua \\ De Motril desembarcó, \\ E los discipulos suyos \\ Esta imágen con fervor \\ Santo dejaron posada, \\ Cabe da la poblacion \\ De nuestra antigua Madrid ${ }^{93}$.
}

Nella commedia analizzata di Calderón de la Barca, Origen, pérdida y restauración de la Virgen del Sagrario, si fa riferimento a quest'immagine, la cui appartenenza agli apostoli la renderebbe più che preziosa. La venerazione da parte di questi, poi, certamente offriva un ottimo argomento a chi era interessato affinché il culto delle immagini si espandesse: se gli amici del Cristo avevano portato con loro un'immagine della Vergine e ad essa avevano attribuito adorazione, tanto più i fedeli cristiani dovevano prenderne esempio. Tra l'altro è una costante nelle immagini spagnole la presunta appartenenza agli apostoli. A Zaragoza sorge un importantissimo santuario dove è conservata l'immagine della Virgen del Pilar. La leggenda di quest'immagine vuole che la Vergine stessa abbia dato all'apostolo Giacomo una sua effige all'alba della partenza dell'apostolo per l'evangelizzazione in Spagna, affinché l'immagine potesse dargli forza e spronare gli infedeli alla conversione ${ }^{94}$.

Nella commedia di Rojas Zorilla vengono date da Fernando una serie di precise indicazioni cronologiche tese a dare ulteriore importanza all'immagine di Atocha. Secondo le parole di Fernando questa sarebbe giunta in Spagna sette anni prima che Maria morisse e cioè nell'anno cinquanta:

Pues si el año de cincuenta

A Madrid nos trasladó

Desde Antioquía nuesa imágen

Nueso Pedro Vice-Dios,

Luego no hay duda alguna

\footnotetext{
92 Idem.

93 Idem.

94 Victor TURNER e Edith TURNER, Image and Pilgrimage in Christian Culture, New York 1978, p. 75.
}

Poder y religión en la Hispania Medieval y Moderna Hispania Sacra 56 (2004) 


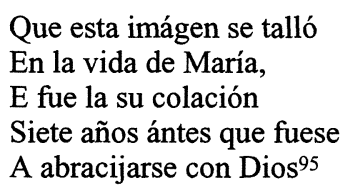

Non c'è dubbio quindi che l'immagine fu intagliata quando la Vergine era ancora in vita. Questo aspetto chiaramente ne garantisce la somiglianza e ne legittima il culto. Il racconto continua con un elogio di Maria fino a giungere al momento in cui l'immagine della Vergine si perse. Con l'arrivo degli arabi nella penisola iberica, l'immagine miracolosamente «si nascose»:

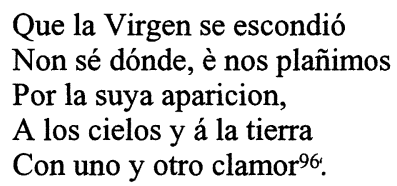

La Vergine non apparve, ma fortunatamente la sua effige restò impressa come una reliquia ed un'immagine della vecchia Señora de Atocha è conservata anche da Fernando:

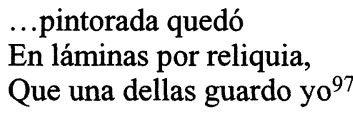

A questo punto dell'opera di Rojas Zorilla viene descritta la statua della Virgen de Atocha, assisa in trono e con una corona «alta un dito» dello stesso materiale dell'immagine; la sua veste è un manto color oro che copre la Vergine fino ai piedi «Para honestarla más bien»; sul lato sinistro due lettere: la «T» e la «O» che stanno per «teotoca», ${ }^{98}$ ossia Madre di Dio; Spiega Fernando che la «O» del «Verbo divino / Semeja la Encarnacion», mentre «T» rappresenta Dio e quindi la «O» inscritta nella «T» è simbolo dell'Incarnazione, dell'ipostatica unione; La Vergine ha il volto scuro, «Morena tiene la faz», onesti e gravi sono gli occhi e guardano affabilmente i giusti e severamente i peccatori; in braccio il bambino Gesù, che stretto vicino al cuore riceve un libretto dalla Madre:

Esta es mia morena dama,

A quien mio casto amor,

\footnotetext{
${ }_{95}$ Francisco de ROJAS ZORRILlA, «Nuestra Señora de Atocha»..., p. 472.

96 Ibidem, p. 473.

97 Idem.

98 Teotokos. Il dogma di «Maria Madre di Dio» fu affermato durante il Concilio di Efeso (431).
}

Poder y religión en la Hispania Medieval y Moderna

Hispania Sacra 56 (2004) 
Sin haberla vista nunca,

Mil ternuras la indilgó 99

Per Rosa l'immagine della Vergine è soltanto un pezzo di legno, ma Fernando sostiene che pur non essendo essa stessa il suo archetipo, le assomiglia e questo basta perché le si dedichi venerazione:
Esta imágen non es madre
De Dios, sandia mora, non;
Pero basta que semeje
La misma madre de Dios ${ }^{100}$;

e veramente sarà oggetto di venerazione quest'immagine da parte di Fernando che non vorrà staccarsene quando Rosa se ne approprierà nemmeno $\mathrm{a}$ costo della sua stessa vita.

\section{MIRACOLI DELLA VERGINE.}

Allo stesso modo delle altre immagini incontrate nel corso del nostro studio, anche la Vergine di Atocha compie dei miracoli. Il primo di questi è l'intervento prodigioso che nel primo atto rende sordi i soldati arabi i quali non possono così rispondere al comando di Rosa di uccidere Fernando e Limonada. Il cristiano ha appena recuperato il ritratto della Vergine al che Rosa gli impone di ridarlo. La risolutezza di Fernando però è così determinata che egli preferisce morire anziché restituire la pittura della Madonna. Rosa comanda i suoi soldati di uccidere i due e Fernando invoca la protezione della Vergine:

$$
\begin{aligned}
& \text { ¡Facedlos sordos, mi Vírgen, } \\
& \text { O ciegos, si sordos non, } \\
& \text { E será un milagro á tempo!101 }
\end{aligned}
$$

I soldati non rispondono al comando resi sordi da un intervento prodigioso. L'azione principale del secondo atto è costituita dalla ricerca dell'immagine. Il personaggio di Gracián è presentato come un infaticabile indagatore della misteriosa scomparsa della Vergine:

Non dejé de escodriñar

Santuario, ermita y templo

Por ver si encuentrara á la Vírgen ${ }^{102}$

\footnotetext{
${ }^{99}$ Francisco de ROJAS ZORRILlA, «Nuestra Señora de Atocha»..., p. 473.

100 Idem.

101 Ibidem, p. 474.
} 
Già alla fine del primo atto si era accennato alla futura ricerca; ora nella seconda parte la scena centrale si svolge di notte e vede coinvolti tutti i personaggi cristiani nell'affannosa azione. Il ritrovamento è preceduto da una visione di Gracián. Nel letto durante il sonno Gracián vede scendere dai cieli Giacobbe con degli angeli e posare sulle alture dell'Atochar la Vergine col bambino; da quelle alture vede salire verso i cieli una forte luce ed in questo modo è sicuro che l'immagine si trovi proprio lì. I cristiani così si riversano sul monte e chiedono a piena voce un intervento divino affinché possano ritrovare l'immagine. Una serie di miracoli quindi precede la scoperta della Virgen de Atocha: una voce si ode e indica il posto dov'è occultata l'immagine; la terra si apre prodigiosamente ed una luce da dentro abbaia la vista dei presenti; si odono suoni di strumenti e l'immagine viene miracolosamente fuori dalla terra. Precedentemente si era supposto che l'immagine fosse stata perduta durante un incendio. Ora però allo scoprirsi della Vergine Leonor esprime tutta la sua meraviglia nel vedere che essa è ancora integra, intatta:

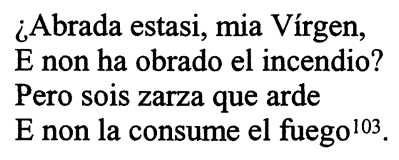

Altre leggende ci propongono degli incendi ai quali le immagini della Vergine sarebbero miracolosamente scampate. Nei Milagros de Nuestra Señora, Gonzalo de Berceo racconta di un miracolo avvenuto a Mont san Michele in Normandia. Un terribile incendio devastò il monastero che sorge sull'isola e tutto tranne l'immagine della Vergine andò bruciato:

Maguer que fue el fuego tan fuert e tan quemant, nin plegó a la dueña nin plegó al infant, solamente el fumo no se llegó a ello, $\mathrm{ni} \cdot 1$ nució más que nuzo yo al bispo don Tello ${ }^{104}$.

Un'altra leggenda è raccolta da Alfonso X nelle Cantigas de Santa Maria. L'episodio riguarda le profanazioni dei mori ${ }^{105}$; questi distrussero un villaggio nei pressi Martos e abbattuta la chiesa della Vergine, portarono via la statua in

\footnotetext{
102 Ibidem, p. 484.

103 Idem.

104 Carlo BERETTA (a cura di), Miracoli della Vergine, cit., p. 562; Il miracolo è il n. 14: La imagen respetada.

105 Como Santa Maria guardou a su majestade / que no recebesse dano de muitos tormentos / que lle fazian os kouros; (Ibidem, pp. 962-967).
}

Poder y religión en la Hispania Medieval y Moderna

Hispania Sacra 56 (2004) 
essa venerata. Dopo vari tentativi di distruzione dell'immagine, decisero di darla alle fiamme, ma nulla successe alla Vergine:

E metérona no fogo mui grand', e jouv' y dous dias;

mas o que en Babilonia guardou no forn' Ananias

e Misael o manyno e o tercer, Azarias,

guardou aquesta do fogo, que sol non lle noziu nada ${ }^{106}$.

Il fatto che l'immagine sia scampata ad un incendio proprio quando i protestanti si davano un gran da fare per ridurre le immagini in cenere, assume un forte significato politico-religioso: «They have often been destroyed, their images have been burnt; but sooner or later they have revived» ${ }^{107}$. Un altro immancabile miracolo è l'intervento della Vergine durante la battaglia tra mori e cristiani. Nella lotta s'invoca l'intercessione di Maria e prontamente gli effetti della richiesta si manifestano:

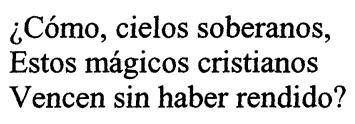

L'ultimo miracolo di cui è artefice la Vergine operante tramite la sua immagine è il risuscitamento delle figlie di Gracián, uccise dal padre vistosi senza scampo di fronte alla minaccia araba. Alla fine della commedia si assiste al prodigio: Leonor ed Elvira sono inginocchiate presso l'altare dove è stata posta l'immagine di Atocha recentemente ritrovata. Sulle loro gole ci sono i segni dell'accoltellamento:

$$
\begin{aligned}
& \text { ¿No conoceis el milagro? } \\
& \text { La Vírgen del Atochar } \\
& \text { Las dos ha resocitado }{ }^{109} \text {. }
\end{aligned}
$$

106 Nelle Cantigas de Santa Maria, è proposto un miracolo attribuito proprio alla Virgen de Atocha. Una povera donna di un villaggio nei pressi di Madrid, si recò un giorno a raccogliere il grano. In quella circostanza il suo giovane figlio ingerì una spiga e il suo ventre s'ingrossò a dismisura tanto da ridurlo in fin di vita. La madre portò così il piccolo ad Atocha e lo depose davanti all'altare. Subito dopo il piccolo fu spogliato e miracolosamente i presenti videro uscire la spiga per intero dal lato sinistro del ventre del bambino; (Ibidem, pp. 1096-1100).

107 Victor TURNER e Edith Turner, Image and Pilgrimage..., p. 199.

108 Francisco de ROJAS ZORRILLA, «Nuestra Señora de Atocha»..., p. 490.

${ }^{109}$ Ibidem, p. 492. 


\section{CONCLUSIONI.}

Rileggendo le opere teatrali possiamo stabilire le somiglianze e le differenze tematiche in cui esse vengono coinvolte. Dato comune, mi sembra una certa indipendenza dell'immagine e una forte personificazione di questa che nell'ambito dell'opera calderoniana, ad esempio, la porta a sottrarsi al volere del vescovo Urbano che avrebbe preferito portarla in salvo dalla minaccia araba, mentre nel caso dell'opera di Fajardo Acevedo, a decide la città in cui farsi posare dagli angeli che la trasportano pellegrini. In quest'ultima opera le è addirittura riservato lo spazio scenico di un qualsiasi altro personaggio e poco ci manca che si muova indipendentemente.

Altro fattore importante d'unione è senza dubbio la corrispondenza tra il movimento di Riconquista e le immagini mariane. Nel caso della Vergine del Sagrario l'immagine è nascosta all'arrivo degli arabi e miracolosamente ritrovata al momento della riconquista di Toledo. Nel caso della Vergine de las Angustias l'immagine è protagonista della vittoria stessa contro gli arabi, così come nel caso di Nuestra Señora de Atocha, immagine precedentemente scomparsa all'arrivo degli infedeli nella penisola:

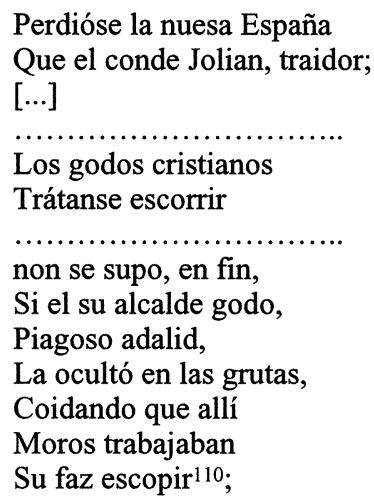

La storia delle immagini spagnole ha in questo elemento, nell'occultazione cioè o miracolosa sparizione delle immagini a causa del pericolo musulmano, un punto tradizionalmente comune. L'immagine di Atocha, «si nasconde», fuggendo in questo modo al pericolo arabo. La statua della Vergine del Sagrario, sarà posta in fondo ad un pozzo per poi essere ritrovata all'alba della Riconquista. Ma altre immagini spagnole subirono la stessa sorte. Si ricordi ad esempio la patrona stessa della Spagna, la Vergine di Guadalupe, immagine

110 Ibidem, pp. 473-474.

Poder y religión en la Hispania Medieval y Moderna Hispania Sacra 56 (2004) 
venerata in Extremadura nella provincia di Cáceres, a Guadalupe dove sorge un santuario-monastero meta di uno dei più importanti pellegrinaggi spagnoli. Quando fu ritrovata, si capì che l'immagine era stata nascosta circa sei secoli prima dai cavalieri di don Rodrigo, l'ultimo re visigoto, colui a cui la tradizione addita le disgrazie dell'invasione araba. ${ }^{11}$ Una leggenda vuole che sia stato Leandro, spaventato dall'invasione dei saraceni, ad occultare l'immagine insieme ad alcune reliquie di suo fratello san Fulgenzio e ad una campana. ${ }^{112}$ Un'altra storia ancora è molto simile a quelle raccontate. Si tratta della leggenda della Vergine di Monserrat, immagine venerata nell'omonimo centro catalano. La tradizione vuole che quest'immagine sia stata ritrovata nell' 888 tra le rocce di Montserrat. Le cronache raccontano che l'effige della Vergine sia stata portata da Gerusalemme a Barcellona e di lì sulle alture di Montserrat per scampare alla profanazione saracena. ${ }^{113}$ Esiste quindi una continuità di storie, un influenzarsi delle tradizioni che vogliono gli apostoli i portatori delle immagini della Vergine in Spagna e l'occultazione di queste di fronte al pericolo arabo. La loro strategica collocazione nei santuari, a detta di Turner, avrebbe poi assunto col passare dei secoli una precisa valenza politica, di autonomia religiosa della nazione spagnola e sarebbe stata finalizzata allo sviluppo della venerazione delle immagini «iberiche»; in particolare la leggenda del Pilar, del trasporto dell'immagine della Vergine effettuato dall'apostolo Giacomo, assumerebbe l'aspetto emblematico di questa impresa:

Catholic Spain, in opposition to iconoclastic Islam, used icons and images as mobilizing points. In rivalry with Rome for the leadership of Christendom's struggle with Islam, Spain miraculously imported an apostle of her town, St. James, to counterpose SS. Peter and Paul, and in her traditions linked him with her own major Marian shrine, that of the Virgin Pilar ${ }^{114}$.

Ulteriore elemento d'unione è la funzione principale che la monarchia assume nell'ambito della promozione del culto delle immagini. Nell'opera di Calderón ai fini della scoperta dell'immagine del Sagrario è decisivo l'intervento della sovrana. Nell'opera di Fajardo Acevedo è Giovanni d'Austria a invocare l'intervento mariano per domare la rivolta araba e a concedere la proprietà del terreno dove sarebbe sorta la nuova basilica in onore dell'immagine. Nel caso della Vergine di Atocha non è un reale a scoprire l'immagine ma Gracián, personaggio nobile e comunque relazionato con la monarchia. Il fatto è facilmente giustificabile vista la realtà dell'epoca e la nota indipendenza dello stato spag-

\footnotetext{
111 Victor TURNER e Edith TURNER, Image and Pilgrimage..., p. 44.

112 Ibidem, p. 45.

113 Ibidem, p. 170.

114 Idem.
} 
nolo dalla Chiesa tanto che la storia della Controriforma dimostra il ruolo fondamentale che ebbe la monarchia spagnola nella «purificazione» ${ }^{115}$ che avvenne all'interno della Chiesa ed è noto ad esempio l'interesse di Filippo II per il recupero di reliquie e la promozione del culto delle immagini ${ }^{116}$. Nelle tre opere studiate, inoltre, le immagini mariane assumono nell'ambito della comunità la funzione assunta altrove proprio dalle reliquie. La loro presenza garantisce un punto di unione per tutti i fedeli e ne benedice le terre. La loro funzione di patronato viene esercitata allo stesso modo di quella dei resti dei martiri. Nelle tre opere le immagini mariane intervengono attivamente a contenimento della minaccia musulmana e in funzione protettiva: l'immagine delle Vergine de las Angustias è portata a mo' di palladio così come i bizantini usavano mostrare agli eserciti nemici le reliquie della Vera Croce. Ed è sempre sottolineata l'iconoclastia dei musulmani: in Nuestra Señora de Atocha Celin rovina templi e brucia immagini cristiane; in Origen de Nuestra Señora de las Angustias Avenfarax desidera profanare l'immagine della Vergine.

Infine l'origine dell'immagine della Vergine del Sagrario, così come quella della Vergine de las Angustias, è mitica. Il tempo della loro realizzazione si perde nel vorticoso susseguirsi dei secoli e l'immagine stessa trascende in questo modo la natura materiale a cui altrimenti sarebbe costretta ${ }^{117}$. Ragione, questa, funzionale nel racconto a supporto della credenza nel potere taumaturgico delle immagini. Nel caso della Vergine di Atocha, invece, il tempo della sua origine è delineato con estrema precisione da parte dell'autore, ma si capisce che proprio quel chiarimento è funzionale alla giustificazione del potere dell'immagine, potere che avrebbe ricevuto dalla Vergine stessa ancora in vita al tempo della realizzazione della statua. Sia nel caso della Vergine del Sagrario che della Vergine di Atocha, poi, si sottolinea l'origine acheropita dell'immagine, elemento che invece non è presente nella commedia di Fajardo Acevedo.

115 Salvador De MADARIAGA, Storia della Spagna, Rocca San Casciano 1966, p. 33.

116 Ricordiamo che Calderón lavorò come drammaturgo di corte per Filippo II.

117 Anche in Nuestra Señora de Atocha la materialità dell'immagine viene sfocata con l'informazione data circa l'incertezza che ruota attorno al legno in cui sarebbe stata intagliata.

Poder y religión en la Hispania Medieval y Moderna

Hispania Sacra 56 (2004) 